\title{
The life cycle of Haemogregarina bigemina (Adeleina: Haemogregarinidae) in South African hosts
}

\author{
Angela J. Davies ${ }^{1}$ and Nico J. Smit ${ }^{2}$ \\ ${ }^{1}$ School of Life Sciences, Faculty of Science, Kingston University, Kingston upon Thames, Surrey KT1 2EE, UK; \\ ${ }^{2}$ Department of Zoology and Entomology, Faculty of Natural Sciences, University of the Free State, Bloemfontein 9300, South \\ Africa
}

Key words: Adeleina, Haemogregarinidae, Haemogregarina bigemina, Gnathia africana, fish parasites, blood parasites, transmission, life cycle

\begin{abstract}
Haemogregarina bigemina Laveran et Mesnil, 1901 was examined in marine fishes and the gnathiid isopod, Gnathia africana Barnard, 1914 in South Africa. Its development in fishes was similar to that described previously for this species. Gnathiids taken from fishes with H. bigemina, and prepared sequentially over 28 days post feeding (d.p.f.), contained stages of syzygy, immature and mature oocysts, sporozoites and merozoites of at least three types. Sporozoites, often five in number, formed from each oocyst from 9 d.p.f. First-generation merozoites appeared in small numbers at 11 d.p.f., arising from small, rounded meronts. Mature, second-generation merozoites appeared in large clusters within gut tissue at 18 d.p.f. They were presumed to arise from fan-shaped meronts, first observed at 11 d.p.f. Third-generation merozoites were the shortest, and resulted from binary fission of meronts, derived from second-generation merozoites. Gnathiids taken from sponges within rock pools contained only gamonts and immature oocysts. It is concluded that the development of $H$. bigemina in its arthropod host illustrates an affinity with Hemolivia and one species of Hepatozoon. However, the absence of sporokinetes and sporocysts also distances it from these genera, and from Karyolysus. Furthermore, H. bigemina produces fewer sporozoites than Cyrilia and Desseria, although, as in Desseria, Haemogregarina (sensu stricto) and Babesiosoma, post-sporogonic production of merozoites occurs in the invertebrate host. The presence of intraerythrocytic binary fission in its fish host means that H. bigemina is not a Desseria. Overall it most closely resembles Haemogregarina (sensu stricto) in its development, although the match is not exact.
\end{abstract}

In a partial systematic revision of the Adeleiorina (Apicomplexa), Siddall (1995) placed fish haemogregarines in the genera Cyrilia, Desseria and Haemogregarina (sensu lato), and those from chelonians in the genus Haemogregarina (sensu stricto). Members of the genera Cyrilia Lainson, 1981 and Haemogregarina (sensu stricto) Danilewsky, 1885 were partially characterised by vermicular meronts in vertebrate erythrocytes, while those in the genus Desseria Siddall, 1995 lacked erythrocytic merogony. Two genera, Cyrilia and Desseria, underwent development in leech hosts as well as in fishes. In Siddall's scheme, the fish haemogregarine Haemogregarina bigemina Laveran et Mesnil, 1901, was grouped with Haemogregarina (sensu lato). Presumably this placing occurred because $H$. bigemina was known to undergo binary fission within fish erythrocytes (see Laird 1953), but much of the evidence for its development in an invertebrate host was considered circumstantial (see Davies 1982).

Studies on the biology of $\mathrm{H}$. bigemina have led to the conclusion that it is probably transmitted by haematophagous praniza larvae of isopods of the genus Gnathia Leach, 1814, which act as temporary ectoparasites of fishes (Davies 1981). At a study site in Wales in 1976, the haemogregarine was observed commonly, occurring in all specimens of intertidal fish (blennies), Lipophrys (Blennius) pholis, over $5.0 \mathrm{~cm}$ in length (Davies and Johnston 1976). However, the infection was first detected in young fish too small to have been bitten by the only leech (Oceanobdella blennii) known to exist on blennies in Wales. Furthermore, H. bigemina occurred at a location where this leech was not known, and was acquired by young blennies in a season when the leech was known not to feed. Larval gnathiid isopods were, in contrast, common at the study site, they fed on fish all year, and some contained stages resembling those occurring in the development of haemogregarines (Davies and Johnston 1976). A greater variety of development stages, presumed to be those of $H$. bigemina, were found in the anterior hindgut of praniza larvae during a second study in Wales in 1982, lending further support for its transmission by gnathiids (Davies 1982).

Haemogregarina bigemina is not confined to the fish, L. pholis. It occurs in a variety of fishes in widely separated geographical locations (see Davies 1995a). Preliminary investigations in Portugal and in South Africa, also support transmission of the haemogregarine by gnathiids (Davies et al. 1994, Smit and Davies 1999, Davies and Johnston 2000) rather than by leeches. 
Recently, H. bigemina has been examined in detail in some marine fishes and gnathiids at De Hoop Nature Reserve and at Jeffreys Bay, South Africa. This study, like previous ones, strongly supports transmission of the haemogregarine by isopods. It also suggests a life cycle unlike that of typical members of the genera Cyrilia, Desseria or Haemogregarina.

\section{MATERIALS AND METHODS}

In South Africa, clinids, Clinus superciliosus (Linnaeus, 1758) and Clinus cottoides Valenciennes, 1836 were captured in rock pools at Koppie Alleen, De Hoop Nature Reserve during April, 1998 and 2000, and at Jeffreys Bay in January 1999. Rocksucker, Chorisochismus dentex (Pallas, 1769), were caught only at Jeffreys Bay in January 1999. Following capture and identification, using methods which have been described elsewhere (Smit and Davies 1999), these fishes were maintained singly, in pairs, or in small groups (3-4 fishes) in buckets of fresh, aerated seawater. This allowed their gnathiid ectoparasites, identified as Gnathia africana Barnard, 1914 (see Barnard 1914, Smit et al. 1999), to be left undisturbed and monitored for periods up to $24 \mathrm{~h}$. Subsequently, the fishes were measured and blood smears were prepared either from heart blood or by snipping a few gill filaments. Blood smears were fixed in absolute methanol, stained by standard Giemsa's stain and screened for $H$. bigemina at $\times 100$ magnification with a Zeiss Axioskop photomicroscope. Measurements were made with an eyepiece graticule and stage micrometer.

When gnathiids had fed to repletion on clinids and rocksucker (between 1-24 h), they were drawn up in broadmouthed pipettes and examined in watch glasses of seawater under a low power $(\times 3, \times 10)$ binocular microscope. This allowed their condition to be assessed, and they could be graded according to size of praniza instar (P1, P2 or P3). Some pranizae were screened for $H$. bigemina immediately following feeding (see below). Others were transferred to small jars of fresh seawater, where they were kept in the dark at between $18-22^{\circ} \mathrm{C}$ for periods up to 28 days post feeding (d.p.f.). Their seawater was replaced at least twice weekly and gnathiids were examined daily under a binocular microscope to monitor their condition and to look for signs of moulting to the next instar or to an adult stage.

Gnathiids were prepared for screening either immediately or on each of 1-28 d.p.f. on clinids and rocksucker. They were removed individually from jars of seawater with a broadmouthed pipette, placed on paper towels to drain surface seawater, crushed, and smeared whole between two glass slides. They were then fixed in absolute methanol, stained, and screened as for blood films (above).

Gnathiids were also retrieved from sponges to assess the prevalence of the haemogregarine in the general population of G. africana, rather than in those known to have fed on infected fishes. Sponges, Hymeniacedon sp., which line the pools in which clinids and rocksucker occur, were collected at low tide with a sharp knife at De Hoop. In the laboratory, these sponges were dissected apart in small dishes of seawater under a low power binocular microscope $(\times 3, \times 10)$. Three stages of segmented (unfed) zuphea larvae $(\mathrm{Z} 1, \mathrm{Z} 2, \mathrm{Z3})$ and replete praniza larvae (P1, P2, P3), and adult males of $G$. africana, which were located near the osculum of many sponges, were extracted with fine brushes, and drained of seawater on paper towels. They were then crushed and smeared between glass slides, fixed, stained and screened as above.

Giemsa-stained smears from G. africana (Figs. 1-17) and blood films from $C$. superciliosus were used to construct a proposed life cycle for H. bigemina in these hosts (Figs. 1839).

\section{RESULTS}

Table 1 records the species of clinids and rocksucker captured at De Hoop and Jeffreys Bay, their number, length, praniza and haemogregarine burdens. No other metazoan ectoparasites were detected on fishes. In Table 2 the gnathiids are classified by instar. First-stage pranizae (P1) were the most common feeding stage on C. superciliosus, $C$. cottoides and Ch. dentex, whereas third-stage pranizae (P3) were found least often. Ninetyseven of 168 pranizae from $C$. superciliosus and $C$. cottoides at De Hoop were screened for stages of $H$. bigemina, the rest were used in life-cycle (manuscript in preparation) and morphological studies of $G$. africana (Smit et al. 1999). At Jeffreys Bay, 106 larval gnathiids were screened for the haemogregarine from a total of 243 (180 pranizae recorded in Table 1, and a further 63 pranizae from 19 C. superciliosus, which were not measured). Remaining gnathiids from Jeffreys Bay were used for life-cycle and morphological studies as at De Hoop. Pranizae P1 and P2 kept in small jars of seawater were found to moult to $\mathrm{Z} 2$ and $\mathrm{Z} 3$ respectively at around 8-10 d.p.f., whereas P3 pranizae moulted into adults between 10-17 days following the last blood meal.

The intraerythrocytic and extracellular stages of $H$. bigemina seen in blood smears from the various species of fishes, agreed in size and morphology with those recorded previously for this species (see Laird 1953, Davies 1982, 1995a, Smit and Davies 1999). In contrast to the observations of Laird (1953), no intraleucocytic stages were seen. Prevalence of infection was usually $<1.0$ parasites/1,000 erythrocytes, although in five fish (all C. superciliosus), 10-15/1,000 erythrocytes were infected. These intraerythrocytic and extracellular stages (see Figs. 20-26) were similar to those reported by Smit and Davies (1999).

The stages seen in smears taken from G. africana (see Figs. 1-17, 27-39) at De Hoop and Jeffreys Bay included free gamonts (Figs. 1, 27) resembling those seen in the erythrocytes of fishes with H. bigemina, or more deeply staining gamonts, some with a pronounced cap. These gamonts were found immediately after pranizae had fed on fishes with $H$. bigemina, and commonly for up to 6 d.p.f., and in all three sizes of pranizae (P1, P2, P3). Exceptionally, unchanged gamonts were found 18 d.p.f. in two third-stage larvae (P3). Pairing of gamonts (syzygy) was recorded for up to 6 d.p.f. (Figs. 2, 28). It proved to be the most difficult stage to locate. The form presumed to be the 


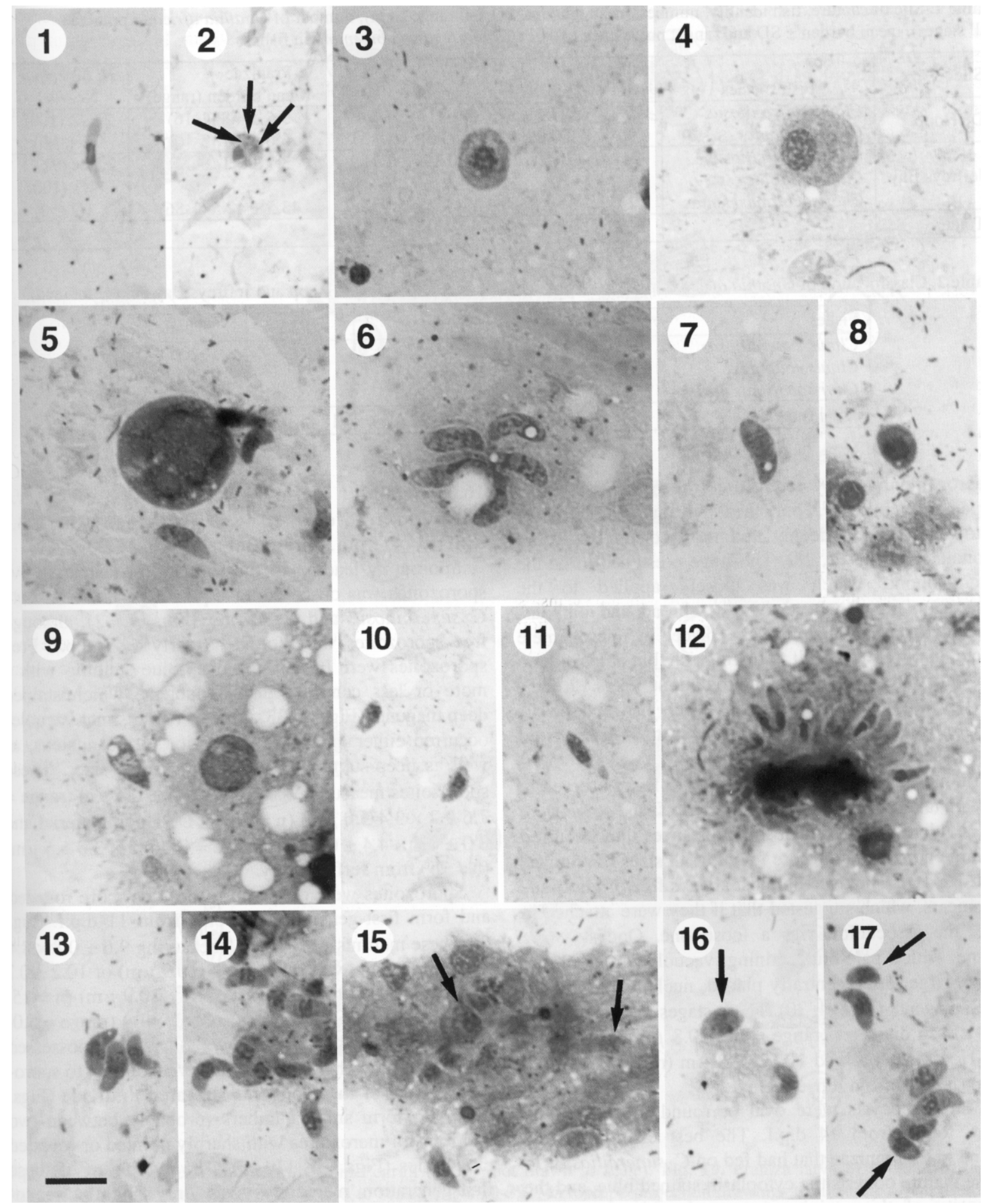

Figs. 1-17. Giemsa-stained smears from Gnathia africana taken from fishes with Haemogregarina bigemina. Background contains bacterial cocci and rods. Fig. 1. Free gamont resembling those seen in blood films from fishes. Fig. 2. Syzygy. Macrogamont with clearly discernible nucleus closely associated microgamont with three visible microgamete nuclei (arrows). Figs. 3, 4. Immature oocysts at different stages of development. Fig. 5. Maturing oocyst with at least four nuclei. A few secondgeneration merozoites lie near the oocyst. Fig. 6. Sporogony leading to the formation of five sporozoites. Fig. 7. Free mature sporozoite. Fig. 8. First-generation meront. Fig. 9. Free sporozoite (left) and dividing first-generation meront (right). Figs. $10,11$. First-generation merozoites. Fig. 12. Second-generation meront producing slender, immature merozoites. Figs. 13, 14. Mature second-generation merozoites in clusters. Fig. 15. Second-generation merozoites enveloped by gut tissue (arrows). Fig. 16. Dividing third-generation meront (arrow). Fig. 17. Third-generation merozoites (arrows). Scale bar $=10 \mu \mathrm{m}$ for all figures. 
Table 1. Site of capture, fish identity, number, mean length \pm SD and range (mm); number of Gnathia africana pranizae (all stages), mean burden \pm SD and range; prevalence (\%) of Haemogregarina bigemina in fishes.

\begin{tabular}{|l|l|c|c|c|c|c|}
\hline \multirow{2}{*}{ Site } & \multicolumn{3}{|c|}{ Fishes } & \multicolumn{2}{c|}{ Pranizae } & H. bigemina \\
& \multicolumn{1}{|c|}{ Fish species } & No. & Mean length (range) & No. & Mean burden (range) & No. $(\%)$ \\
\hline \multirow{2}{*}{ De Hoop } & Clinus superciliosus & 22 & $127.2 \pm 37.6(71-219)$ & 117 & $5.5 \pm 4.8(1-16)$ & $22 / 22(100)$ \\
& Clinus cottoides & 9 & $80.9 \pm 10.5(57-96)$ & 51 & $5.6 \pm 3.1(2-10)$ & $9 / 9(100)$ \\
\hline \multirow{3}{*}{ Jeffreys Bay } & Clinus superciliosus & 24 & $126.0 \pm 24.8(100-195)$ & 89 & $3.7 \pm 3.1(0-12)$ & $22 / 24(91.7)$ \\
& Clinus cottoides & 1 & 102 & 4 & & $1 / 1(100)$ \\
& Chorisochismus dentex & 2 & 85 and 201 & 87 & $43.5 \pm 42.5(1-86)$ & $1 / 2(50)$ \\
\hline Total & & 58 & & 348 & & 55 \\
\hline
\end{tabular}

Table 2. Classification of Gnathia africana pranizae from fishes by stage (instar) (De Hoop and Jeffreys Bay data combined).

\begin{tabular}{|l|c|c|c|c|c|}
\hline Fishes & No. & P1 & P2 & P3 & Total \\
\hline Clinus superciliosus & 46 & 142 & 53 & 11 & 206 \\
Clinus cottoides & 10 & 31 & 22 & 2 & 55 \\
Chorisochismus dentex & 2 & 61 & 21 & 5 & 87 \\
\hline Total (prevalence) & & $234(67.3 \%)$ & $96(27.6 \%)$ & $18(5.1 \%)$ & $348(100 \%)$ \\
\hline
\end{tabular}

macrogamont largely retained its haemogregarine-like appearance initially, but then became broader, the cytoplasm stained deeply and the nucleus was more pronounced (Figs. 2, 28). The stage presumed to be the microgamont, which was closely applied to the macrogamont, also became rather broad and gibbous. The microgamont nucleus was replaced by microgamete nuclei that were difficult to distinguish, but at least three or four were visible per microgamont (Figs. 2, 28). Syzygy was seen in gnathiids which had fed on $C$. superciliosus with $H$. bigemina but in none taken from other fishes.

Immature oocysts (Figs. 3, 29) were first observed in smears taken from $G$. africana at 7 d.p.f. and some were still evident at 19 d.p.f. In some instances they occurred in large numbers, and were found in all sizes of pranizae (P1, P2, P3). They were almost always free of gut tissue in smears, which suggested that if they were attached in life, the association was a loose one. Oocysts were round, with a pale-blue staining, vacuolated cytoplasm, and a large, often centrally placed, nucleus that stained deep magenta (Figs. 4, 30). These stages measured $9.4 \pm$ $0.8 \mu \mathrm{m}$ in diameter $($ range $=8.3-10.8 \mu \mathrm{m})(\mathrm{n}=15)$ in De Hoop material and $10.3 \pm 2.2 \mu \mathrm{m}($ range $=6.0-14.0$ $\mu \mathrm{m})(\mathrm{n}=15)$ from Jeffreys Bay.

Mature oocysts were oval or round in outline and were found from 14 d.p.f. The best examples were found in P2 pranizae that had fed on C. superciliosus. In these mature oocysts the cytoplasm stained blue, and the intensity of this staining increased with age of the oocyst. The cytoplasm was also a little vacuolated (Fig. 5). Nuclei stained deep magenta and were either single or, when sporogony had begun, from two to eight nuclei occurred within a single oocyst (Figs. 5, 31). Five nuclei were the most common numbers observed in dividing oocysts. These older oocysts measured $18.0 \pm 4.6 \times 11.5$ $\pm 1.7 \mu \mathrm{m}$ when oval $($ range $=14-24 \times 10.0-16.8 \mu \mathrm{m})$ $(\mathrm{n}=10)$ and $18.0 \pm 1.2 \mu \mathrm{m}$ across when round (range
16.0-19.1 $\mu \mathrm{m})(\mathrm{n}=4)$ at De Hoop, and $14.3 \pm 0.4 \times 11.8$ $\pm 1.1 \mu \mathrm{m}$ (oval only) (range $=14.0-15.0 \times 10.0-13.0$ $\mu \mathrm{m})(\mathrm{n}=4)$ from Jeffreys Bay.

Sporogony leading to the formation of at least five sporozoites was observed 11 d.p.f. of pranizae on both C. superciliosus and Ch. dentex (Figs. 6, 32), although free sporozoites were found as early as 9 d.p.f. Free sporozoites were broad, and deep-blue staining with a more or less centrally placed nucleus, which stained deep magenta (Figs. 7, 33). One or two distinct vacuoles occurred either anterior or posterior to the nucleus, as well as deep-staining granules of various sizes. These sporozoites measured $8.7 \pm 0.7 \times 4.4 \pm 0.4 \mu \mathrm{m}$ (range $=$ 7.6-9.2 $\times 3.4-5.0 \mu \mathrm{m})(\mathrm{n}=20)$ in De Hoop material and $8.0 \pm 0.8 \times 4.4 \pm 0.6 \mu \mathrm{m}($ range $=7.0-9.5 \times 3.0-5.5 \mu \mathrm{m})$ $(\mathrm{n}=25)$ from Jeffreys Bay.

Sporozoites were observed to become more rounded and form first-generation meronts from 11 d.p.f. (Fig. $8)$. These meronts were small, measuring $9.6 \pm 0.8 \times 8.4$ $\pm 1.2 \mu \mathrm{m}$ when oval (range $=8.4-10.9 \mu \mathrm{m})$ or $10.2 \pm 0.3$ $\mu \mathrm{m}$ across when round $($ range $=10.1-10.9 \mu \mathrm{m})(\mathrm{n}=15)$ at De Hoop and $6.8 \pm 1.1 \mu \mathrm{m}$ (round only) (range $=5.0$ $9.08 \mu \mathrm{m})(\mathrm{n}=4)$ from Jeffreys Bay. They possessed similar staining characteristics and vacuolation to sporozoites. Each of these meronts appeared to divide (Figs. 9,34 ) to form small numbers (probably between two and four) of merozoites with sharply pointed or rounded extremities (Figs. 10, 11, 35). The cytoplasm of these first-generation merozoites was only slightly vacuolated. Roughly one quarter to one third of the merozoite cytoplasm stained pale cream, while the remaining cytoplasm stained pale blue (Figs. 10, 11). The nucleus lay much nearer to one end of this stage than the other, separating the cream cytoplasm from the blue. The nucleus itself was composed of loosely arranged chromatin. These first-generation merozoites measured $6.6 \pm 0.4 \times 2.5 \pm 0.2 \mu \mathrm{m}($ range $=5.9-7.6 \times 2.1-2.9 \mu \mathrm{m})$ $(\mathrm{n}=15)$. 


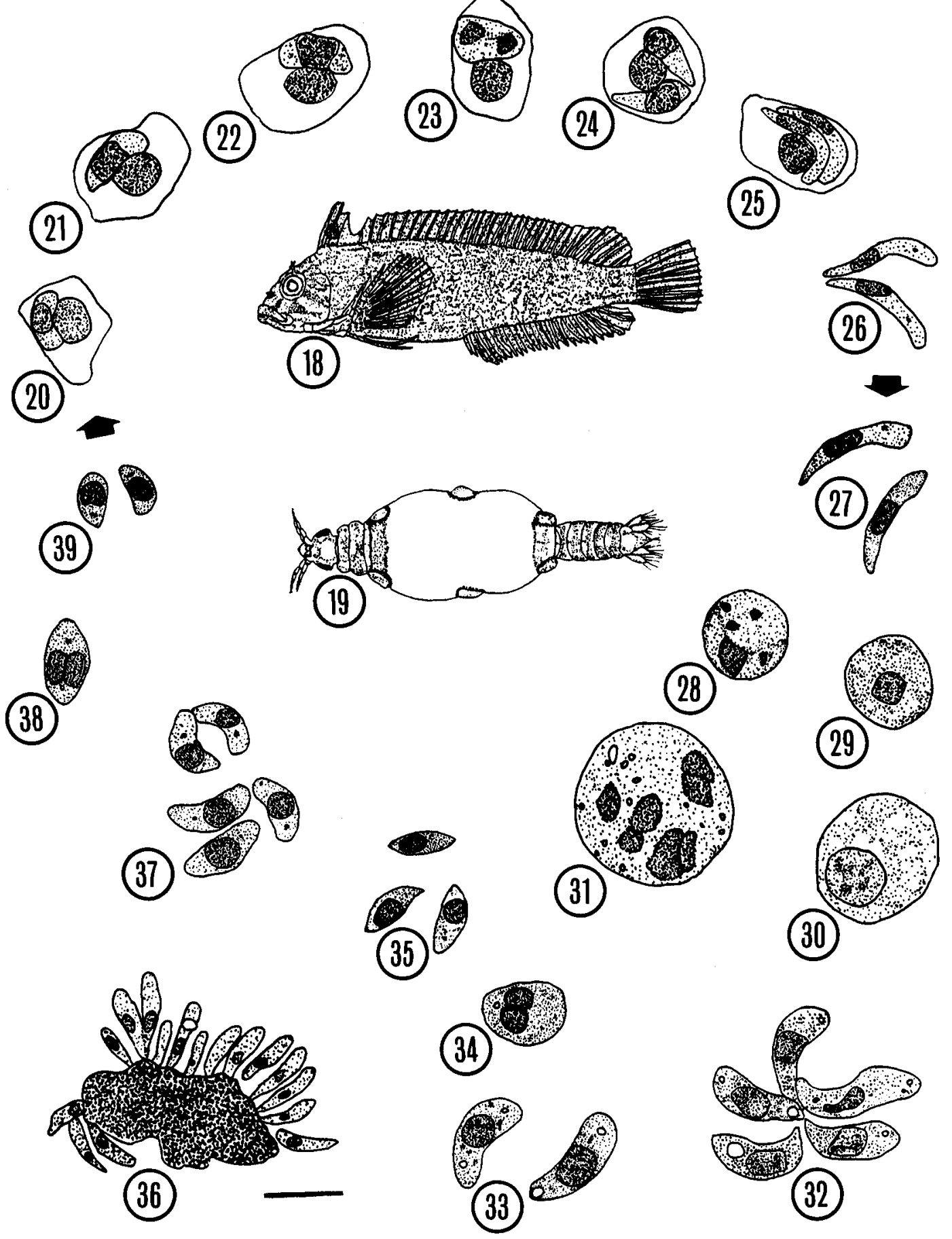

Fig. 18. Clinus superciliosus redrawn from Penrith (1969) (not drawn to scale). Fig. 19. Praniza larva of Gnathia africana redrawn from Smit et al. (1999) (not drawn to scale). Figs. 20-39. Microscope projection drawings to illustrate a proposed life cycle for Haemogregarina bigemina. Figs. 20-26. Stages within the peripheral blood of C. superciliosus; Figs. 27-39. Stages within G. africana. Arrows indicate transfer of haemogregarine from one host to another. Fig. 20. Intraerythrocytic trophozoite. Figs. 21, 22. Intraerythrocytic meronts. Fig. 23. Pregamontic binary fission. Fig. 24. Immature, paired, intraerythrocytic gamonts. Fig. 25. Mature, paired, intraerythrocytic gamonts. Fig. 26. Paired gamonts freed from host erythrocyte. Fig. 27. Free gamonts like those seen in C. superciliosus. Fig. 28. Syzygy. Macrogamont and associated microgamont with three distinct microgamete nuclei. Figs. 29, 30. Immature oocysts at different stages of development. Fig. 31. Maturing oocyst. Fig. 32. Sporogony leading to the formation of five sporozoites. Fig. 33. Free mature sporozoites. Fig. 34. Dividing first-generation meront. Fig. 35. Firstgeneration merozoites. Fig. 36. Second-generation meront producing slender, immature merozoites. Fig. 37. Mature secondgeneration merozoites. Fig. 38. Dividing third-generation meront. Fig. 39. Third-generation merozoites. Scale bar $=10 \mu \mathrm{m}$ for Figs. 20-39. 
Second-generation meronts were large and were also detected at 11 d.p.f. They were fan-shaped, producing at least 16 slender, immature merozoites (Figs. 12, 36). Mature, second-generation merozoites were first observed at 18 d.p.f. (Figs. 13, 14, 37). These secondgeneration merozoites measured, $8.0 \pm 0.5 \times 2.6 \pm 0.2$ $\mu \mathrm{m}$ (range $=7.1-9.2 \times 2.5-3.4 \mu \mathrm{m})(\mathrm{n}=20)$ at De Hoop and $7.9 \pm 0.6 \times 2.4 \pm 0.2 \mu \mathrm{m}$ (range $=6.5-8.5 \times 2.0-2.5$ $\mu \mathrm{m})(\mathrm{n}=10)$ from Jeffreys Bay. They were larger than first-generation merozoites, and were more numerous, often occurring in large clusters, enveloped by gut tissue (Fig. 15), suggesting that this stage of merogony develops in the gut (anterior hindgut?) lining. The cytoplasm of second-generation merozoites was pale blue staining, slightly vacuolated and the nuclear chromatin was loosely arranged as in first-generation merozoites (Figs. 13, 14). The nucleus lay roughly half way down the merozoite (Fig. 37).

Second-generation merozoites were observed at 18 d.p.f. to contain two nuclei (= third-generation meronts) (Figs. 16, 38). These were presumed to form thirdgeneration merozoites by division into two (binary fission). Third-generation merozoites were the shortest merozoites observed, measuring $5.9 \pm 0.2 \times 2.5 \pm 0.2$ $\mu \mathrm{m}($ range $=5.0-6.3 \times 2.1-2.9 \mu \mathrm{m})(\mathrm{n}=15)$. These small merozoites (Figs. 17, 39) were interpreted as the final stages of development in G. africana. They were seen only in preparations made at De Hoop, and, like secondgeneration merozoites, they were found enveloped by gut tissue. Mixed populations of sporozoites, and first, second and third-generation merozoites were seen in two P2 gnathiids from De Hoop.

In 88 gnathiids examined from sponges at De Hoop, nine (five P1, four P2) contained gamonts and one (P2) contained immature oocysts resembling those described above. No other stages were seen in these gnathiids.

All smears from the gut of gnathiids contained background bacterial flora (rods and cocci) (Figs. 1-17). These were presumed to be symbiotic bacteria needed to digest fish blood or to supply essential amino acids or vitamins (see Juilfs and Wägele 1987, Davies 1995b).

\section{DISCUSSION}

The complex relationships among Haemogregarina bigemina, intertidal fishes, and blood-feeding, larval, gnathiid isopods have now been examined in three geographical locations (Wales, Portugal and South Africa). In all cases a high prevalence of the haemogregarine in the fish populations examined has been demonstrated, and these fishes have been shown to act as hosts for large numbers of gnathiids (Davies and Johnston 1976, Davies 1982, Davies et al. 1994, Smit and Davies 1999, this study). In the present study in southern Africa, the large burden of gnathiid ectoparasites carried by three species of intertidal fishes (Clinus superciliosus, Clinus cottoides and Chorisochismus dentex) infected with $H$. bigemina was apparent.
Fifty-eight specimens of these fishes carried 348 pranizae of Gnathia africana in three larval stages (P1, P2, P3). Although in a preliminary report from South Africa, three Caligus sp. and one unidentified leech were found on clinids at Jeffreys Bay (Smit and Davies 1999), no leeches or other ectoparasites that might transmit $H$. bigemina were detected in the present study.

Also in the current study, to add weight to the evidence for a relationship between the haemogregarine and gnathiids, the stages observed in Giemsa-stained smears from $G$. africana, taken at different time points following feeding, included syzygy, oocysts, sporozoites, and apparently three generations of merozoites. The morphology of these stages, and the fact that they exist in gnathiids taken from fishes infected only with $H$. bigemina in their blood stream, leads to the conclusion that they must be the development stages of the haemogregarine in its invertebrate host.

It is perhaps not surprising that $H$. bigemina undergoes development in $G$. africana. Some stages of development of $H$. bigemina have been observed previously in gnathiids, both in the northern hemisphere (Davies and Johnston 1976, Davies 1982, Davies et al. 1992) and in South Africa (Smit and Davies 1999, Davies and Johnston 2000). Davies and Johnston (1976) reported stages from Welsh gnathiids, which, in the light of current observations, were likely to have been an oocyst and sporozoites (their figs. 9, 10). Davies (1982, 1995a) illustrated further stages of development from Welsh gnathiids, which included syzygy and oocyst development. The forms that she interpreted in micrographs as sporoblasts can now be identified as sporozoites, and her sporozoites were probably merozoites. Davies et al. (1994) also identified syzygy and oocysts in Portuguese gnathiids which had fed on fishes with $H$. bigemina, while Smit and Davies (1999) reported syzygy in $G$. africana from southern Africa. Davies and Johnston (2000) illustrated, but did not describe in detail, an oocyst, a sporozoite, and numerous merozoites freed from the gut lining of G. africana taken from $C$. superciliosus infected with $H$. bigemina.

Leeches have traditionally been identified as the vectors of haemogregarines from aquatic hosts, especially fishes. It is a departure from this tradition, therefore, to discover that arthropods transmit $H$. bigemina between intertidal fishes in both the northern and southern hemispheres. Arthropods generally act as vectors for the haemogregarines of semi-aquatic and terrestrial vertebrates (see Davies and Johnston 2000), and these haemogregarine genera include Karyolysus Labbé, 1894, Hepatozoon Miller, 1908, and Hemolivia Petit, Landau, Baccam et Lainson, 1990. Haemogregarina bigemina in gnathiids resembles Hemolivia sp. in ticks, Amblyomma sp. and Hyalomma aegyptium (Petit et al. 1990, Landau and Paperna 1997, Smallridge and Paperna 1997), and Hepatozoon lygosomarum Allison et Desser, 1981 in the mite, Ophionyssus 
scincorum (Allison and Desser 1981), in that sporogony appears to be confined to the gut of an arthropod. However, its oocysts are not irregular or star-shaped, as in Hemolivia sp. (Petit et al. 1990), and its oocysts are not large and located in the haemocoel as in many Hepatozoon (see Smith 1996). Furthermore, H. bigemina has not been observed to produce sporokinetes or sporocysts, as in Karyolysus, Hemolivia, and Hepatozoon (Svahn 1975, Petit et al. 1990, Smith 1996).

The development of $H$. bigemina in gnathiids more closely resembles the stages of haemogregarines that have been observed in leeches, than in other arthropods. Stages that have been reported from leeches include those of Cyrilia, Desseria and Haemogregarina (sensu stricto). The development in leeches of Babesiosoma, a genus thought to be closely related to haemogregarines, is also confirmed (Barta and Desser 1989).

Cyrilia is characterised by sporogony in intestinal epithelial cells, but unlike in $H$. bigemina, oocysts produce 20 or more naked sporozoites which are presumed to migrate to the salivary glands of the leech, where they are infectious to a new host (Lainson 1981).

In Desseria, following syngamy in the leech, the zygote undergoes multiple sporogonic divisions producing 16-32 sporozoites, numbers which far exceed those found in H. bigemina (4-8 sporozoites, often 5 per oocyst). However, the subsequent behaviour of sporozoites of Desseria and those of $H$. bigemina is similar. In both cases sporozoites appear to infect the gut epithelium of the invertebrate host where merogony occurs. However, merogony appears to result only in four merozoites in Desseria (see Siddall and Desser 1993), but evidence for at least three generations of distinct morphological types of merozoites have been found in $H$. bigemina.

Members of the genus Haemogregarina (sensu stricto), such as Haemogregarina balli Paterson et Desser, 1976 from turtles, are characterised in leeches by sporogony in the intestinal epithelium producing eight sporozoites from a single germinal centre, and post-sporogonic production of merozoites in extraintestinal leech tissues (see Siddall 1995). Interestingly, the development of Babesiosoma stableri Smitter et McGhee, 1961 in a leech (Batracobdella picta) also involves an oocyst with eight sporozoites and postsporogonic production of merozoites in the salivary glands (Barta and Desser 1989). The development of $H$. bigemina in $G$. africana seems to match the development of Haemogregarina (sensu stricto) and Babesiosoma in leeches most closely, except that five sporozoites appear to be the common number produced from each oocyst. Five nuclei within the dividing oocysts of $H$. bigemina from Welsh gnathiids were also illustrated by Davies (1995a) (see her fig. 16g). The production of five sporozoites by the oocyst is an unusual number biologically, matched only perhaps by the existence of five arms on the stellate oocyst of
Hemolivia spp. (see Smallridge and Bull 1999). Merozoite production appears to occur in the gut tissue of $G$. africana, and currently there is no evidence of extraintestinal merogony.

In studies of the relationship between $H$. bigemina and gnathiids, using crush/smear techniques (as in this study), and previous histological methods (unpublished), the haemogregarine has not been demonstrated in the salivary glands of the isopods. However, it is impossible to be certain that the haemogregarine never enters the salivary cells. Gnathiids which had fed on haemogregarine-infected fishes carried a fair burden of parasites (Table 1) in this study, as did gnathiids taken directly from sponges. In the laboratory, as in Welsh studies, intertidal fishes of all ages readily ate larval gnathiids (see Davies 1982). Therefore, H. bigemina is probably transmitted when infected gnathiids are ingested by fishes, rather than by bite. This might also explain the observation in Wales that young fish display the infection soon after metamorphosis, when they acquire the feeding habits of adult fish (see Davies 1982). At this stage it is not clear whether infection with $H$. bigemina in gnathiids can accumulate over their lifecycle stages between successive feeds and moults. This has been suggested to occur in ticks with Hemolivia mariae (Smallridge and Bull 1999). Biological transmission in the laboratory would be necessary to establish whether this is the case.

The question arises where $H$. bigemina should be placed taxonomically amongst haemogregarines and dactylosomatids. Its development in its vertebrate host involves division within erythrocytes, which excludes it from the genus Desseria and typically from Hepatozoon, except for two species of Hepatozoon described recently by Smith et al. (2000). Its division in erythrocytes is also characteristically into two vermicular individuals, which excludes it from the genera Babesiosoma and Dactylosoma. In its invertebrate, arthropod host, the development of $H$. bigemina appears to have most in common with the development of Haemogregarina (sensu stricto) in leeches, but it is not a close match, and its affinity with some aspects of the development of Hemolivia is reemphasised. Until the precise destination of merozoites within the gnathiid have been established, it is difficult to determine where $H$. bigemina should be placed. The fact that it develops in an aquatic vertebrate and an arthropod, rather than a leech, is not enough in our opinion to assign it in a new genus. Lankesterella spp. for example, probably utilise vertebrate, annelid and arthropod hosts, as well as other means of transmission (see Desser 1993).

Levine (1988) listed 85 species of marine fishes in 59 genera as hosts for H. bigemina, and Smit and Davies (1999) reported a further two new host fishes. In the current study, Ch. dentex was found to be another new host. Haematophagous larval gnathiids are also widely spread throughout marine and sometimes, brackish, 
waters (Monod 1926, Cohen and Poore 1994, Grutter and Poulin 1998), where, in some instances they have been reported to injure fish in blood feeding (see Davies 1995b). The broad distribution of gnathiids and their feeding behaviour may explain the seemingly wide host range and almost cosmopolitan spread of $H$. bigemina.

Haemogregarina bigemina was first described at the beginning of the last century in northern France by Laveran and Mesnil (1901). It is perhaps fitting that at the turn of this century, its life cycle is largely resolved.
Acknowledgements. The authors gratefully acknowledge the funding provided for this study by the marine resource programme of the National Research Foundation of South Africa, The Royal Society of London (A.J.D.) and The Canon Collins Educational Trust for Southern Africa (N.J.S.). M.R.L. Johnston was immensely helpful in processing isopod larvae for examination.

\section{REFERENCES}

ALLISON B., DESSER S.S. 1981: Developmental stages of Hepatozoon lygosomarum (Doré 1919) comb. n. (Protozoa: Haemogregarinidae), a parasite of a New Zealand skink, Leiolopisma nigriplantare. J. Parasitol. 67: 852-858.

BARNARD K.H. 1914: Contributions to the crustacean fauna of South Africa. 1. Additions to the marine Isopoda. Ann. S. Afr. Mus. 10: 197-230.

BARTA J.R., DESSER S.S. 1989: Development of Babesiosoma stableri (Dactylosomatidae; Adeleina; Apicomplexa) in its leech vector (Batracobdella picta) and the relationship of the dactylosomatids to the piroplasms of higher vertebrates. J. Protozool. 36: 241-253.

COHEN B.F., POORE G.C.B. 1994: Phylogeny and biogeography of the Gnathiidae (Crustacea: Isopoda) with descriptions of new genera and species, most from southeastern Australia. Mem. Mus. Victoria 54: 271-397.

DAVIES A.J. 1981: A scanning electron microscope study of the praniza larva of Gnathia maxillaris Montagu (Crustacea, Isopoda, Gnathiidae), with special reference to the mouthparts. J. Nat. Hist. 15: 545-554.

DAVIES A.J. 1982: Further studies on Haemogregarina bigemina Laveran \& Mesnil, the marine fish Blennius pholis L., and the isopod Gnathia maxillaris Montagu. J. Protozool. 29: 576-583.

DAVIES A.J. 1995a: The biology of fish haemogregarines. Adv. Parasitol. 36: 117-203.

DAVIES A.J. 1995b: Studies on the gut flora of the haematophagous fish parasite Gnathia maxillaris Montagu. Bull. Eur. Assoc. Fish Pathol. 15: 32-35.

DAVIES A.J., EIRAS J.C., AUSTIN R.T.E. 1994: Investigations into the transmission of Haemogregarina bigemina Laveran and Mesnil, 1901 (Apicomplexa: Adeleorina) between fishes in Portugal. J. Fish Dis. 17: 283-289.

DAVIES A.J., JOHNSTON M.R.L. 1976: The biology of Haemogregarina bigemina Laveran \& Mesnil, a parasite of the marine fish Blennius pholis Linnaeus. J. Protozool. 23: 315-320.

DAVIES A.J., JOHNSTON M.R.L. 2000: The biology of some intraerythrocytic parasites of fishes, amphibia and reptiles. Adv. Parasitol. 45: 1-107.

DESSER S.S. 1993: The Haemogregarinidae and Lankesterellidae. In: J.P. Kreier (Ed.), Parasitic Protozoa. Vol. 4. Second Edition. Academic Press, New York, pp. 247-272.
GRUTTER A.S., POULIN R. 1998: Intraspecific and interspecific relationships between host size and the abundance of parasitic larval gnathiid isopods on coral reef fishes. Mar. Ecol. Prog. Ser. 164: 263-271.

JUILFS H.B., WÄGELE J.W. 1987: Symbiontic bacteria in the gut of the blood-sucking Antarctic fish parasite Gnathia calva (Crustacea: Isopoda). Mar. Biol. 95: 493499.

LAINSON R. 1981: On Cyrilia gomesi (Neiva \& Pinto, 1926) gen. nov. (Haemogregarinidae) and Trypanosoma bourouli Neiva \& Pinto, in the fish Synbranchus marmoratus: simultaneous transmission by the leech Haementeria lutzi. In: E.U. Canning (Ed.), Parasitological Topics: A Presentation Volume to P.C.C. Garnham, F.R.S. on the Occasion of his $80^{\text {th }}$ Birthday, 1981. Society of Protozoologists, Lawrence, Kansas, pp. 150-158.

LAIRD M. 1953: The protozoa of New Zealand intertidal zone fishes. Trans. R. Soc. N.Z. 81: 79-143.

LANDAU I., PAPERNA I. 1997: The assignment of Hepatozon mauritanicum, a tick-transmitted parasite of the tortoise, to the genus Hemolivia. Parasite 4: 365-367.

LAVERAN A., MESNIL F. 1901: Deux hémogrégarines nouvelles des poissons. C. R. Acad. Sci. Paris 133: 572577.

LEVINE N.D. 1988: The Protozoan Phylum Apicomplexa. Vol. 1. CRC Press, Boca Raton, Florida, 203 pp.

MONOD T. 1926: Les Gnathiidae. Essai monographique. (Morphologie, biologie, systematique). Mem. Soc. Sci. Nat. Maroc 13: 1-667.

PENRITH M. 1969: The systematics of the fishes of the family Clinidae in South Africa. Ann. S. Afr. Mus. 55: 1121.

PETIT G., LANDAU I., BACCAM D., LAINSON R. 1990: Description et cycle biologique d'Hemolivia stellata $\mathrm{n}$. g. n. sp., hémogrégarine de crapauds brésiliens. Ann. Parasitol. Hum. Comp. 65: 3-15.

SIDDALL M.E. 1995: Phylogeny of adeleid blood parasites with a partial systematic revision of the haemogregarine complex. J. Euk. Microbiol. 42: 116-125.

SIDDALL M.E., DESSER S.S. 1993: Ultrastructure of merogonic development of Haemogregarina (sensu lato) myoxocephali (Apicomplexa: Adeleina) in the marine leech Malmiana scorpii and localization of infective stages in the salivary glands. Eur. J. Protistol. 29: 191-201. 
SMALLRIDGE C.J., BULL C.M. 1999: Transmission of the blood parasite Hemolivia mariae between its lizard and tick hosts. Parasitol. Res. 85: 858-863.

SMALLRIDGE C.J., PAPERNA I. 1997: The tick-transmitted haemogregarinid of the Australian sleepy lizard Tiliqua rugosa belongs to the genus Hemolivia. Parasite 4: 359363.

SMIT N.J., DAVIES A.J. 1999: New host records for Haemogregarina bigemina from the coast of southern Africa. J. Mar. Biol. Assoc. U.K. 79: 933-935.

SMIT N.J., VAN AS J.G., BASSON L. 1999: A redescription of the adult male and praniza of Gnathia africana Barnard,

Received 29 September 2000
1914 (Crustacea, Isopoda, Gnathiidae) from southern Africa. Folia Parasitol. 46: 229-240.

SMITH T.G. 1996: The genus Hepatozoon (Apicomplexa: Adeleina). J. Parasitol. 82: 565-585.

SMITH T.G., KIM B., HONG H., DESSER S.S. 2000: Intraerythrocytic development of species of Hepatozoon infecting ranid frogs: evidence for convergence of life cycle characteristics among apicomplexans. J. Parasitol. $86: 451-458$.

SVAHN K. 1975: Blood parasites of the genus Karyolysus (Coccidia, Adeleidae) in Scandinavian lizards. Description and life cycle. Norw. J. Zool. 24: 277-295.

Accepted 14 December 2000 